\title{
Graphene in analytical science
}

\author{
Martin Pumera $\cdot$ Ronen Polsky $\cdot$ Craig Banks
}

Published online: 21 September 2014

(C) Springer-Verlag Berlin Heidelberg 2014

We are excited to present to you a topical collection of articles on graphene in analytical science. Since the reintroduction of graphene to the scientific community in 2004, it took only a few years before graphene-related analytical applications appeared (Fig. 1). A few years later, in 2010, when the Nobel Prize in Physics was awarded to the scientists who had characterized graphene only 6 years before, the analytical utility of graphene was already well established.

We felt that it would be timely to organize a topical collection on the applications of graphene in the analytical sciences containing high-profile articles from leading groups in the field presented in one volume. This issue should provide readers with a general perspective and a snapshot of the latest cutting-edge research in the field. We are proud to have a collection of very high quality articles which include the use of graphene in mainstream analytical methods.

We thank the editors of Analytical and Bioanalytical Chemistry for their support of this work.

We hope you will enjoy this special issue!

Published in the topical collection Graphene in Analytics with guest editors Martin Pumera, Ronen Polsky, and Craig Banks.

\footnotetext{
M. Pumera $(\bowtie)$

Division of Chemistry \& Biological Chemistry, School of Physical and Mathematical Sciences, Nanyang Technological University, SPMS-CBC-04-07, 21 Nanyang Link, Singapore 637371, Singapore e-mail: pumera@ntu.edu.sg

R. Polsky

Sandia National Laboratories, Biosensors \& Nanomaterials, 1515

Eubank, Albuquerque, NM 87123, USA

C. Banks

Division of Chemistry and Environmental Science, School of Science and the Environment, Manchester Metropolitan University, John Dalton Building Chester Street, Manchester M1 5GD, UK
}

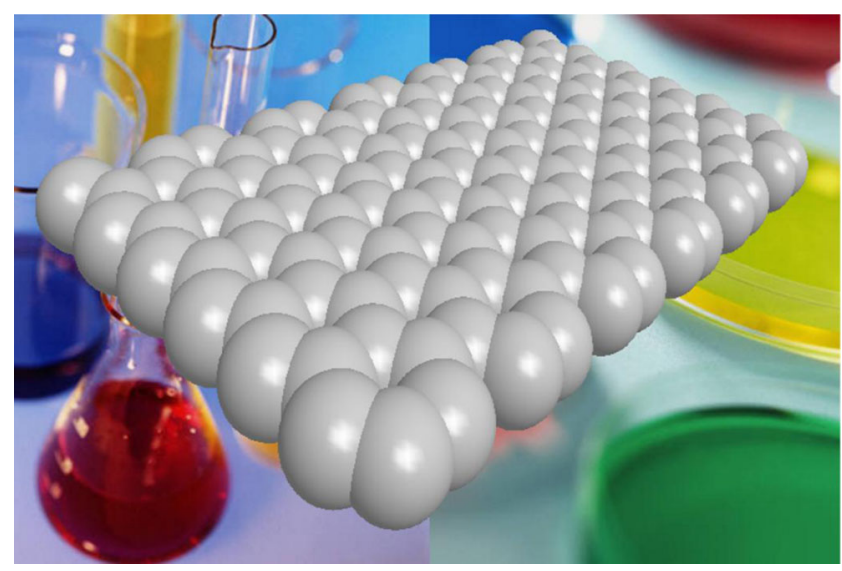

Fig. 1 Graphene-related materials have found applications in analytical chemistry, such as in separations, spectroscopy, and electroanalysis

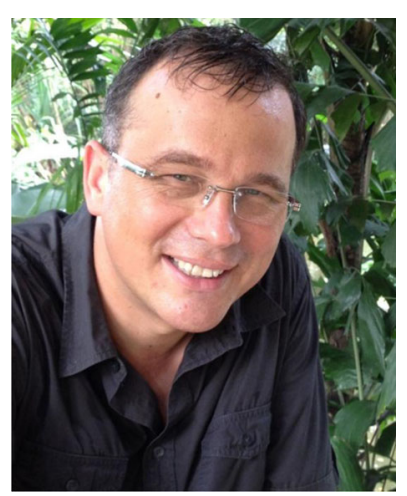

Martin Pumera has been a tenured faculty member at Nanyang Technological University (Singapore) since 2010. He received his $\mathrm{PhD}$ degree from Charles University (Czech Republic) in 2001. After two postdoctoral stays (in the USA and Spain), he joined the National Institute for Materials Science (Japan) in 2006 for a tenure-track arrangement, and stayed there until spring 2008, when he accepted a tenured position at the National Institute for Materials Science. In 2009, he was a recipient of an ERC-StG award. He has broad interests in nanomaterials and microsystems, in the specific areas of electrochemistry and synthetic chemistry of carbon nanomaterials, nanomotors, nanotoxicity, and energy-storage devices. 


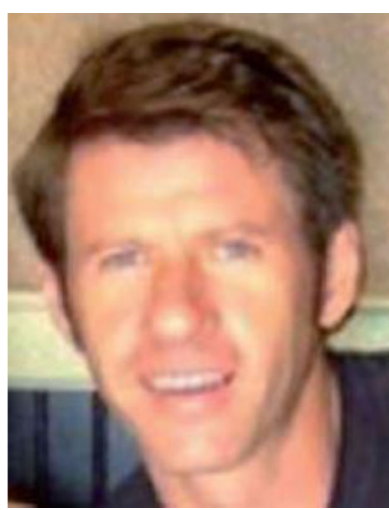

Ronen Polsky is a principal member of the technical staff at Sandia National Laboratories (USA) in the Department of Biosensors and Nanomaterials. $\mathrm{He}$ received his $\mathrm{PhD}$ degree from New Mexico State University (USA) in 2004. This was followed by a postdoctoral fellowship at the Hebrew University of Jerusalem (Isreal) from 2005 to 2006 before he joined Sandia National Laboratories in 2007. His research areas of interest are electrode arrays, novel chemical functionalizations, porous carbons, and three-dimensional graphene.

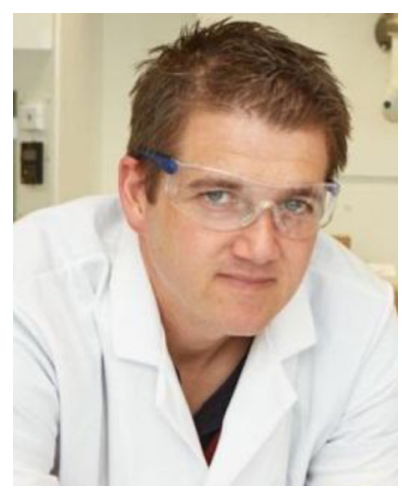

Craig Banks is a Professor at Manchester Metropolitan University and holds a personal chair in electrochemical and nanotechnology. His current research is directed towards the pursuit of studying the fundamental understanding and applications of nanoelectrochemical systems such as graphene, carbon nanotubes, and nanoparticlederived sensors, developing novel electrochemical sensors via screen-printing and related techniques, and energy storage and generation based on graphene composites. 